\title{
Derajat Kesehatan Jasmani dan Postur Siswa Sekolah di Makassar
}

\author{
The Physical Health Status and Posture of Student in Makassar
}

\author{
Muhammad Nadjib Bustan*, Ians Aprilo, Khairil Anwar \\ Fakultas Ilmu Keolahragaan, Universitas Negeri Makassar \\ ('mnbustan@unm.ac.id)
}

\begin{abstract}
ABSTRAK
Masa depan derajat kesehatan fisik bangsa Indonesia ditentukan oleh derajat kesegaran jasmani generasi muda. Karena itu, penting untuk mengetahui bagaimana keadaan kesehatan jasmani generasi muda dengan cara mengukur derajat kesegaran jasmani anak sekolah. Tujuan penelitian ini untuk menentukan derajat kesehatan jasmani anak melalui pengukuran tinggi badan, status gizi, dan postur tubuh anak sekolah. Studi potong-lintang dilaksanakan dengan menarik sampel dari 4 sekolah dasar dan 4 sekolah menengah pertama dalam Kota Makassar. Populasi anak sekolah ini diwakili oleh 252 siswa yang mendapatkan pemeriksaan kesegaran jasmani, dan diantaranya 228 siswa yang mendapatkan pemeriksaan khusus postur memakai Formetric. Hasil penelitian menunjukkan tingginya proporsi anak yang pendek dan sangat pendek $(23,7 \%)$. Proporsi anak dengan status gizi kurus dan sangat kurus sebanyak 29,8\% disertai kelompok kegemukan dan obese 42,1\%. Keadaan postur tubuh (somatotype) berada di luar batas normal dalam bentuk endomorph (bentuk badan gemuk) $36,5 \%$ dan ectomorph(bentuk badan kurus) sebanyak 25,4\%. Gangguan kelurusan tulang belakang (spine misalignment) ditandai dengan kiposis $27,0 \%$, lordosis $21,9 \%$, dan skoliosis $38,2 \%$. Kesimpulan, siswa sekolah masih mempunyai derajat kesehatan jasmani yang rendah dan gangguan postur kelurusan tulang belakang yang tinggi.
\end{abstract}

Kata kunci : Tinggi badan, status gizi, postur

\section{ABSTRACT}

The future of the physical health status of the Indonesian nation is determined by the degree of physical fitnessess of the young generation. Therefore, it is important to know how the status of youth physical health by measuring the degree of physical fitness of school children. The purpose of this study was to determine the degree of physical health of children through measurement of body height, nutritional status, and posture of school children. A cross-sectional studywas conducted by drawing samples from four primary schools and four first middle schools in Makassar City. The schoolchild population was represented by 252 students who received physical fitness checks, and 228 students received special posture tests using Formetric/Pedoscan. The results showed a high proportion of children short and very short (23.7\%). The proportion of children with nutritional status of skinny and very thin as much as 29,8\% accompanied by obesity group and obese 42,1\%. The state of posture (somatotype) was beyond the normal limit in the form of endomorph (body shape fat) 36.5\% and ectomorph (body shapeskiny) as much as 25.4\%. Spinal misalignment was characterized by $27.0 \%$ kyphosis, $21.9 \%$ lordosis, and $38.2 \%$ of scoliosis. In conclusion, school students still have low physical fitness and high spinal misalignment.

Keywords : Height, nutritional status, posture 


\section{PENDAHULUAN}

Masa depan derajat kesehatan fisik bangsa Indonesia ditentukan oleh derajat kesegaran jasmani generasi muda. Oleh karena itu, penting untuk mengetahui keadaan kesehatan jasmani generasi muda dengan melakukan pengukuran derajat kesehatan jasmani anak sekolah. ${ }^{1}$ Siswa sekolah adalah generasi muda pelanjut kehidupan berbangsa untuk berprestasi dalam pembangunan bangsa di masa depan. Untuk maksud tersebut, para anak sekolah selayaknya bisa hidup sehat dan bugar sejak dari kandungan, bayi, usia balita hingga masuk sekolah. ${ }^{2}$

Minimal sejak usia anak, mereka sewajarnya sudah mempunyai tubuh yang tumbuh sehat, segar, dan tegap. Namun demikian, pertumbuhan fisik anak menghadapi berbagai macam tantangan yang memungkinkan terjadi gangguan pertumbuhan fisik dan terjadinya penyakit chronic di masa depan. ${ }^{3}$ Untuk itu, perlu melakukan pemeriksaan secara dini dan tepat waktu.

Derajat kesehatan jasmani dari aspek tinggi badan cukup memprihatinkan, ditandai dengan prevalensi kelompok anak Indonesia yang berstatus tinggi badan pendek (stunting) sebesar 37,2 \%. ${ }^{4}$ Artinya, pertumbuhan tidak maksimal diderita oleh sekitar 8,9 juta anak Indonesia, atau satu dari tiga anak Indonesia. Prevalensi stunting di Indonesia lebih tinggi daripada negara-negara lain di Asia Tenggara, seperti Myanmar (35\%), Vietnam (23\%), dan Thailand (16\%). ${ }^{5}$

Untuk itu, mengatasi masalah ini pemerintah menggalakkan Gerakan 1000 Hari Pertama Kesehatan dengan cara mengatasi masalah gizi dan tinggi badan ini lebih dini sejak masa kehamilan hingga usia 2 tahun pertama, atau 1000 hari pertama kehidupan. Berbagai program dalam Gerakan 1000 HPK ini berupa pemenuhan kebtuhan zat gizi bagi ibu hamil, pemberian tablet zat besi atau $\mathrm{Fe}$, suplementasi besi folat, ASI eksklusif sampai umur 6 bulan, dan setelah umur 6 bulan diberi makanan pendamping ASI (MPASI). ${ }^{6}$

Sasaran yang ingin dicapai pada akhir tahun 2025 disepakati sebagai berikut: (1) Menurunkan proporsi anak balita yang stunting sebesar 40 persen; (2) Menurunkan proporsi anak balilta yang menderita kurus (wasting) kurang dari 5\%; (3) Menurunkan anak yang lahir berat badan rendah sebesar 30\%; (4) Tidak ada kenaikan proporsi anak yang mengalami gizi lebih; (5) Menurunkan proporsi ibu usia subur yang menderita anemia sebanyak 50\%: (6) Meningkatkan prosentase ibu yang memberikan ASI eksklusif selama 6 bulan paling kurang $50 \% .^{5}$

Kesehatan jasmani ditandai dengan berat badan yang ideal sesuai dengan umur dan tinggi badan. Berat badan anak bervariasi dan berhubungan erat dengan tinggi badan dalam menghitung status gizi. Pengukurannya dilakukan dengan memakai WHO Anthro. ${ }^{7}$ Status gizi anak ditandai dengan beban ganda yakni terdapat anak dengan gizi rendah/buruk sebanyak $12,1 \%$ disatu pihak, sementara di pihak lain terdapat gizi lebih (overweight) sebanyak $11,9 \%{ }^{8,9}$

Selain tinggi badan dan berat badan, kesehatan fisik ditandai dengan bentuk tubuh (somatotipe) yang tepat. ${ }^{10}$ Bentuk tubuh anak Indonesia bervariasi dalam bentuk endomorph, mesomorph, ectomorph, dan modifikasi lainnya. ${ }^{11}$

Postur tubuh yang tegap dan lurus diharapkan juga sudah tumbuh kembang selama masa anak. ${ }^{12}$ Berbagai jenis perilaku gerak, aktifitas fisik dan olahraga, termasuk faktor genetik dapat mempengaruhi keadaan postur anak. Proporsi anak dengan gangguan postur terdistribusi dalam bentuk kiposis, lordosis dan skoliosis. ${ }^{13,14}$

Kesehatan jasmani siswa dapat ditentukan oleh status gizi dan postur tubuh. Untuk itu dilakukan pengukuran terhadap kesehatan jasmani yang meliputi tinggi badan, berat badan, status gizi, ketegapan tubuh dan kelurusan tulang belakang.

Untuk melakukan pemeriksaan derajat kesegaran fisik, khususnya postur tubuh anak sekolah dapat dipergunakan berbagai cara pemeriksaan. Dewasa ini pengukuran dilakukan dengan pendekatan teknologi modern. Khusus untuk pemeriksaan kondisi susunan tulang belakang ( $\mathrm{co}$ lumna vertebralis) telah tersedia berbagai alat modern, antara lain Formetric yang digunakan dalam penelitian ini.

Pemeriksaan keadaan susunan tulang belakang sangat penting karena menyangkut postur/ketegapan tubuh, dasar penampilan fisik dan kemampuan berolahraga. Tulang belakang yang mengalami gangguan akan menganggu ketegapan postur, penampilan fisik, kemampuan bermain, dan bertanding olahraga. ${ }^{15}$

Derajat kesehatan jasmani anak ditentukan 
dan diklasifikasi menurut hasil semua pengukuran tersebut.Berdasarkan hasil pengukuran itu dapat dicapai tujuan penelitian ini untuk menentukan derajat kesehatan jasmani anak sekolah berdasarkan penentuan status tinggi badan, status gizi, ketegapan badan, dan kelurusan vertebra (spinal aligment) siswa sekolah di Makassar.

\section{BAHAN DAN METODE}

Studi potong-lintang telah dilaksanakan dengan menarik sampel dari 4 Sekolah Dasar (SD) dan 4 Sekolah Menegah Pertama (SMP) di Kota Makassar jumlah populasi sebanyak 402 siswa SD dan 53 siswa SMP dalam Kota Makassar. Sampel dari kelompok siswa SD ditarik dari kelas 4 dan 5, sedangkan kelompok siswa SMP ditarik dari kelas 1 dan 2, masing-masing sebanyak 25-30 orang per kelas. Kelompok sekolah dasar diambil dari SD. Cilalang, SD. Rappocini, SD. IKIP, dan SD Komplek IKIP. Kelompok SMP diambil dari SMPN 6 Ahmad Yani, SMPN 3 Baji Gau, SMP 13 Tamalate VI, dan SMP 33Tamalate VI.

Populasi anak SD dan SMP yang terpilih diwakili oleh 252 siswa yang mendapatkan pemeriksaan kesegaran jasmani, dan 228 yang mendapatkan pemeriksaan khusus postur memakai Formetric/Pedoscan. Pengukuran tinggi badan dan berat badan dilakukan sewaktu wawancara dalam kunjungan di sekolah masing-masing. Pemeriksaan postur dilakukan di Klinik Olahraga Fakultas Ilmu Ke- olahragaan Universitas Negeri Makassar Makassar. Derajat kesehatan jasmani siswa dilakukan dengan mengukur tinggi badan, berat badan, status gizi, ketegapan tubuh dan kelurusan tulang belakang.

Metode pemeriksaan tinggi badan dilakukan dengan memakai meteran tinggi, status gizi diukur berdasarkan berat badan, sedangkan ketegapan dan kelurusan vertebra dengan memakai alat pemeriksaan khusus Formetric. ${ }^{16}$

\section{HASIL}

Hasil pengukuran tinggi badan dengan memakai standar WHO Height by Age mendapatkan persentase siswa yang sangat pendek $6,6 \%$, pendek $17,1 \%$, normal $75,3 \%$, dan tinggi 0,01 $\%$ (Tabel 1). Hasil pengukuran status gizi dengan memakai standar WHO Weight by Age mendapatkan bahwa siswa yang sangat Kurus $7,9 \%$, Kurus $11,9 \%$, Normal $38,1 \%$, gemuk $12,7 \%$, dan Obesitas 29,4\% (Tabel 1).

Pengukuran postur meliputi pengukuran bentuk fisik tubuh (somatotype) dan ketegapan fisik dengan memakai Pedometric, dan pengukuran kelurusan tulang belakang (spine alignment) dengan memakai Formetric. Distribusi siswa berdasarkan somatotype (bentuk umum tubuh) yaitu dari total 252 responden yang paling tinggi adalah endomorph (agak gemuk) sebanyak 96 siswa $(36,5 \%)$ sedangkan frekuensi yang paling rendah yaitu yang tergolong ectomorph (agak kurus) yaitu sebanyak 64 siswa $(25,4 \%)$. Dengan kata lain, hasil menunjukkan bahwa masih tinggi proporsi bentuk postur endomorph (gemuk) 36,5\%, dan ektomorph (kurus) 25,4\%. Distribusi siswa berdasarkan ketegapan tubuh yaitu dari total 252 respon-

Tabel 1. Distribusi Frekuensi Status Gizi Anak Menurut Tinggi Badan/Umur dan BMI/Umur

\begin{tabular}{|c|c|c|c|c|c|c|c|c|c|c|c|}
\hline \multirow[b]{2}{*}{ Sekolah } & \multicolumn{5}{|c|}{ Status Gizi Menurut Tinggi Badan/Umur } & \multicolumn{6}{|c|}{ Status Gizi Menurut BMI/Umur } \\
\hline & $\begin{array}{l}\text { Sangat } \\
\text { Pendek }\end{array}$ & Pendek & Normal & Tinggi & n & $\begin{array}{l}\text { Sangat } \\
\text { Kurus }\end{array}$ & Kurus & Normal & Gemuk & Obesitas & n \\
\hline SD Rappocini & 2 & 6 & 22 & 0 & 30 & 0 & 8 & 13 & 5 & 4 & 30 \\
\hline SD Cilallang & 5 & 8 & 17 & 0 & 30 & 3 & 4 & 16 & 5 & 2 & 30 \\
\hline SD IKIP 1 & 1 & 2 & 22 & 0 & 25 & 3 & 0 & 9 & 3 & 10 & 25 \\
\hline SD Komp. IKIP & 0 & 6 & 25 & 0 & 31 & 2 & 3 & 12 & 2 & 11 & 31 \\
\hline SMPN 3 & 2 & 4 & 26 & 0 & 32 & 2 & 1 & 15 & 5 & 9 & 32 \\
\hline SMPN 33 & 4 & 6 & 24 & 0 & 34 & 2 & 3 & 15 & 3 & 11 & 34 \\
\hline SMPN 6 & 1 & 5 & 25 & 1 & 32 & 6 & 3 & 6 & 3 & 15 & 32 \\
\hline SMPN 13 & 2 & 6 & 29 & 1 & 38 & 2 & 8 & 10 & 6 & 12 & 38 \\
\hline Jumlah & $\begin{array}{c}17 \\
(6,6 \%)\end{array}$ & $\begin{array}{c}43 \\
(17,1 \%)\end{array}$ & $\begin{array}{c}190 \\
(75,3 \%)\end{array}$ & $\begin{array}{c}2 \\
(0,01 \%)\end{array}$ & $\begin{array}{c}252 \\
(100 \%)\end{array}$ & $\begin{array}{c}20 \\
(7,9 \%)\end{array}$ & $\begin{array}{c}30 \\
(11,9 \%)\end{array}$ & $\begin{array}{c}96 \\
(38,1 \%)\end{array}$ & $\begin{array}{c}32 \\
(12,7 \%)\end{array}$ & $\begin{array}{c}74 \\
(29,4 \%)\end{array}$ & $\begin{array}{c}252 \\
(100 \%)\end{array}$ \\
\hline
\end{tabular}


Tabel 2. Distribusi Siswa Berdasarkan Bentuk Tubuh/Somatotype

\begin{tabular}{ccc}
\hline Variabel & $\mathbf{n = 2 5 2}$ & $\mathbf{\%}$ \\
\hline Bentuk Tubuh & & \\
Endomorph & 92 & 36,5 \\
Mesomorph & 96 & 38,1 \\
Ectomorph & 64 & 25,4 \\
Ketegapan Tubuh & & \\
Lurus & 53 & 21,0 \\
Tegap & 134 & 53,2 \\
Bongkok & 51 & 20,2 \\
Miring & 14 & 5,6 \\
\hline
\end{tabular}

den yang tergolong tegap sebanyak $134(53,2 \%)$ siswa sedangkan yang paling rendah yaitu yang miring sebanyak 14 (5,6\%) siswa. Ketegapan tubuh ditemukan 20,2\% dengan tubuh bongkok (Tabel 2). Hasil pengukuran kelurusan vertebra dengan kiposis (27\%), lordosis $(21,9 \%)$, dan skoliosis $(38,2 \%)$ (Tabel 3).

Hasil analisis kasus ditemukan sebuah kasus gangguan kesehatan jasmani dan postur pada seorang anak yang ditandai dengan fisik yang agak pendek, kurus dan skeliosis (vertebra yang miring ke samping). Kasus ini berupa seorang anak perempuan sekolah menengah pertama, bernama SRH, usia 14 tahun, dengan nomor sepatu 36.

Hasil pemeriksaan fisik menunjukkan tinggi badan 150,8 (agak pendek), berat badan $36 \mathrm{~kg}$ (kurus). Gambaran somatotype adalah ectomorph, dan ketegapan tubuh bentuk bongkok. Pemeriksaan Formetric menggambarkan: Truck balance :2; Kyphosis angle:50; Lordosis angle: 3; Lateral angle : 8. Gambaran hasil pemeriksaan Formetric disajikan dalam Gambar 1 dan Gambar 2.

\section{PEMBAHASAN}

Penelitian terhadap kesehatan jasmani siswa sudah mendapat perhatian dari berbagai peneliti. ${ }^{17-19}$ Indikator pertama kesehatan jasmani ditunjukkan dengan tinggi badan yang sesuai dengan umur. Tinggi badan pendek (stunting) merupakan masalah kesehatan jasmani yang menandai anak Indonesia. Prevalensi stunting anak usia sekolah $35,4 \%$, yakni $41,6 \%$ di perdesaan dan $29,8 \%$ di perkotaan. ${ }^{20}$ Perihal tinggi badan, penelitian ini menemukan stunting terdiri atas 6,6\% sangat pendek, $17,1 \%$ pendek. Keadaan kesehatan jas-
Tabel 3. Hasil Pengukuran Kelurusan Vertebra

\begin{tabular}{lcc}
\multicolumn{1}{c}{ Siswa } & & \\
\hline \multicolumn{1}{c}{ Variabel } & $\mathbf{n}$ & $\mathbf{\%}$ \\
\hline $\begin{array}{l}\text { Trunk Imbalance } \\
\text { Balance }\end{array}$ & 13 & 44,8 \\
$\quad \begin{array}{l}\text { Imbalance } \\
\text { Kyposis }\end{array}$ & 16 & 55,2 \\
$\quad$ Normal & 22 & 75,9 \\
$\quad$ Abnormal & 7 & 24,1 \\
Lordosis & & \\
$\quad$ Normal & 24 & 82,8 \\
$\quad$ Abnormal & 5 & 17,2 \\
Skoliosis & & \\
$\quad$ Normal & 16 & 55,2 \\
$\quad$ Abnormal & 13 & 44,8 \\
Pedoscan & & \\
$\quad$ Balance & 9 & 31,0 \\
Imbalance & 20 & 69,0 \\
\hline$\quad$ & &
\end{tabular}

mani stunting pada masa anak-anak akan mempengaruhi perkembangan kognitif. ${ }^{4,20}$

Status gizi anak Indonesia ditandai de-ngan tingginya stunting, wasting dan overweight. ${ }^{21}$ Kondisi kesehatan fisik anak sekolah berdasarkan status gizi menunjukkan bahwa cukup banyak siswa yang mempunyai kondisi gizi sangat kurus $(7,9 \%)$, kurus $(11,9 \%)$, disertai berat badan lebih (overweight) $(12,7 \%)$ dan, obesitas $(29,4 \%)$. Gambaran keadaan double-burden gizi ini merata hampir mengenai seluruh daerah di Indonesia. ${ }^{22}$

Bentuk tubuh (somatotype) merupakan gambaran fisik yang kasat mata terhadap status gizi yang memberi kesan pertama tentang penampilan fisik seseorang. Penelitian ini menemukan bahwa gangguan bentuk tubuh ditandai dengan masih tingginya proporsi postur endomorph (gemuk) $36,5 \%$, dan ektomorph (kurus) 25,4\%. Gambaran ini selaras dengan beban ganda status gizi anak Indonesia yang ditandai dengan tingginya proporsi anak kurang gizi bersama lebih gizi (obesitas).

Penelitian ini menemukan ketiga bentuk gangguan tulang belakang, yang tersebar dalam bentuk kiposis, lordosis dan skoliosis. Keadaan ini juga terjadi berbagai negara lainnya di dunia, misalnya di Republik Cekoslakia, Bosnia, dan Herzegovina. ${ }^{23,24}$

Kelurusan vertebra sangat dibutuhkan oleh setiap olahragawan karena berhubungan dengan keterampilan olahraga yang dipilihnya, terlebih untuk penampilan dalam olahraga kompetisi. ${ }^{25}$ 


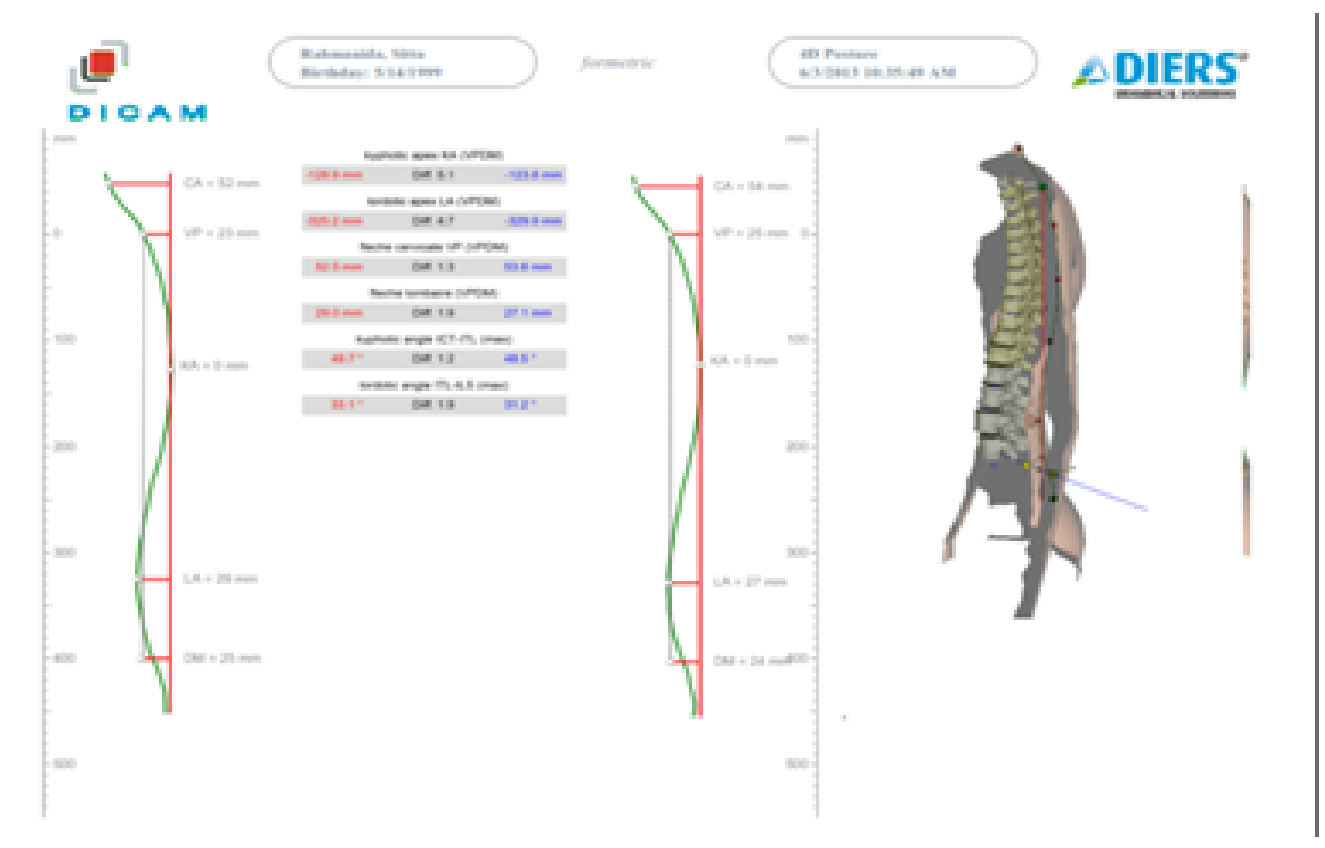

\section{Gambar 1. Hasil Pemeriksaan Formetric Kasus SRH dari Arah Samping/Sagital}

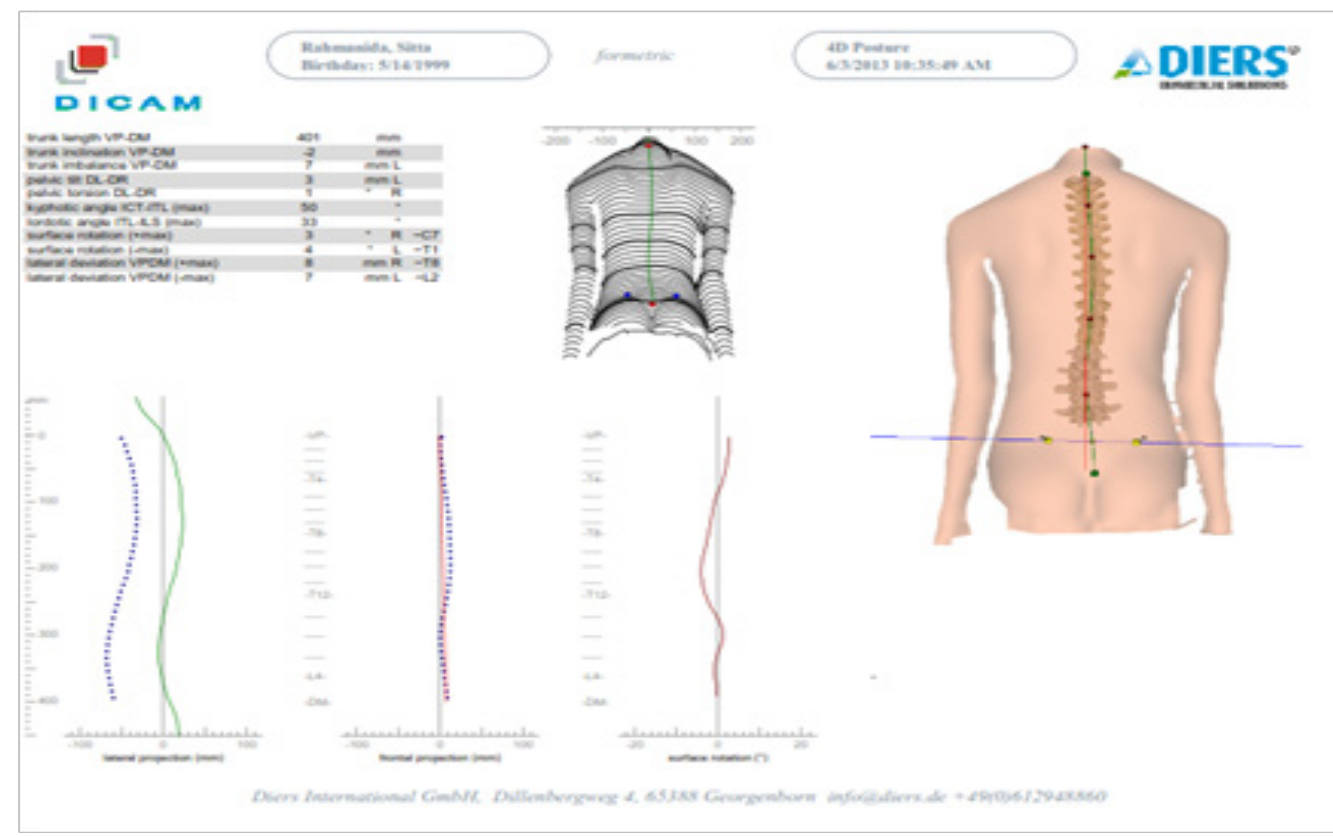

\section{Gambar 2. Hasil Pemeriksaan Formetric Kasus SRH dari Arah Belakang/Dorsal}

Bahkan gangguan kelurusan vertebra ini sudah sampai pada tahap yang memerlukan tindakan operasi (spinal surgery). ${ }^{26}$

Contoh kasus yang dikemukakan telah mendapatkan pemeriksaan kesehatan jasmani lengkap. Pemeriksaan postur meliputi somatotype dan kelurusan vertebra yang dilakukan pada contoh kasus ini dengan memakai alat mutak- hir Formetric yang baru berada di Indonesia pada awal 2010. ${ }^{16}$ Kasus ini menggambarkan secara lengkap hasil pengukuran parameter somatotype dan kelurusan vertebra (spinal aligmnet) disertai dengan gambaran fisiknya. Hasil pemeriksaan fisik kasus ini menunjukkan tinggi badan 150,8 (agak pendek), berat badan $36 \mathrm{~kg}$ (kurus). Gambaran bentuk tubuh adalah endomorph (kurus),dan 
ketegapan tubuh bentuk bongkok. Kasus ini bisa menjadi representasi anak Indonesia dan dunia pada umumnya yang ditandai dengan tubuh pendek (stunting), kurus (wasting), ditambah dengan gangguan kelurusan tulang belakang (spinal misalignment). ${ }^{27}$

\section{KESIMPULAN DAN SARAN}

Dapat disimpulkan bahwa siswa sekolah masih mempunyai derajat kesehatan jasmani yang rendah dan gangguan kelurusan tulang belakang yang tinggi. Diperlukan penelitian lanjut untuk mengindentifikasi faktor penyebab terjadinya derajat kesehatan jasmani yang rendah dan gangguan kelurusan tulang belakang yang tinggi pada anak sekolah.

Untuk menghindari dan mengatasi gangguan postur dan deviasi vertebra, para siswa diharapkan melakukan aktivitas fisik sehari-hari yang ergonomis, termasuk pola duduk selama belajar di sekolah. Dinas Pendidikan bersama dengan sekolah disarankan melakukan pemeriksaan khusus postur dan kelurusan tulang belakang kepada siswa SD, SMP dan SMA se-Kota Makassar yang mempunyai risiko gangguan fisik tersebut; melakukan pelatihan pengukuran kesegaran jasmani kepada guru; melakukan pelatihan kepada guru tentang program latihan pembinaan postur dan fisik siswa; dan mengaktifkan program Usaha Kesehatan Sekolah.

\section{UCAPAN TERIMA KASIH}

Ucapan terima kasih atas bantuan dana dari Dinas Pendidikan Makassar, dan kerjasama yang baik dengan kepala sekolah dan guru di 8 sekolah dasar dan sekolah menengah pertama lokasi penelitian.

\section{DAFTAR PUSTAKA}

1. Kornfält R, Jönsson B, Roslund I. Physical Health Screening of School-Children. Extended Health Care Responsibilities for School-Nurses. Acta Paediatr Scand. 1979 Nov;68(6):879-85.

2. Evan G. Graber. Physical Growth of Infants and Children - Children's Health Issues - MSD Manual Consumer Version [Internet]. MSD Manual. 2017 [cited 2018 Jan 2]. Available from: http://www.msdmanuals.com/home/ children-s-health-issues/growth-and-development/physical-growth-of-infants-and-children.

3. Koleva M, Nacheva A, Boev M. Somatotype and Disease Prevalence in Adults. Rev Environ Health. 2002;17(1):65-84.

4. Kementerian Kesehatan RI. Riset Kesehatan Dasar 2013. Jakarta; 2015.

5. Kementerian Kesehatan RI;, Millennium Challenge Account - Indonesia. Stunting dan Masa Depan Indonesia. Jakarta; 2015.

6. Bappenas. Kerangka Kebijakan Gerakan Nasional Percepatan Perbaikan Gizi dalam Rangka Seribu Hari Pertama Kehidupanersi 11 Sept '12. 2013.

7. WHO. WHO Anthro version 3.2.2, January 2011. WHO. Geneva: World Health Organization; 2011.

8. Global Nutritional Report. Intervention Coverage And Child-Feeding Practices Underlying Determinants Financial Resources And Policy, Legislation, And Institutional Arrangements 2014 Nutrition Country Profile. 2014.

9. Kementerian Kesehatan RI. Keputusan Menteri Kesehatan RI Nomor 1995/Menkes/SK/ XII/2010 tentang Standard Antropometri Penilaian Status Gizi Anak. Jakarta; 2010.

10. BrianMac Sport Coach. Body Type and Build - Somatotype [Internet]. 2017 [cited 2017 Dec 31]. Available from: https://www.brianmac. co.uk/bodytype.htm

11. Widiyani T, Suryobroto B, Budiarti S, Hartana A. The Growth of Body Size and Somatotype of Javanese Children Age 4 to 20 Years. HAYATI J Biosci. 2011 Dec 1;18(4):182-92.

12. Napierkowski DB. Scoliosis: A Case Study in an Adolescent Boy. Orthop Nurs. 2007 May;26(3):147-55.

13. Boulay C, Tardieu C, Hecquet J, Benaim C, Mouilleseaux B, Marty C, et al. Sagittal Alignment of Spine and Pelvis Regulated by Pelvic Incidence: Standard Values and Prediction of Lordosis. Eur Spine J. 2006 Apr;15(4):415-22.

14. Gelb Daniel E. MD; Lenke, Lawrence G. MD; Bridwell, Keith H. MD; Blanke, Kathy RN; McEnery KWM. An Analysis of Sagittal Spinal Alignment in 100 Asymptomatic: Spine. Spine (Phila Pa 1976). 1995;(June 1995). 
15. Dier Medical Solution. Manual Diers Formetric. 2013.

16. Diers Formetric. DIERS formetric 4D. 2014.

17. Rismayanthi C, Or M. Pemeriksaan Kesegaran Jasmani Anak Usia Sekolah Lanjutan. 1983;

18. Johnson J. Postural assessment. Human Kinetics; 2012. $161 \mathrm{p}$.

19. BKKBN. Survei Demografi dan Kesehatan Indonesia 2017 [Internet]. BKKBN. 2017 [cited 2018 Jan 2]. Available from: https://www. bkkbn.go.id/detailpost/bkkbn-survei-demografi-dan-kesehatan-indonesia-2017.

20. Salimar S, Kartono D, Fuada NF, Setyawati B. Stunting Anak Usia Sekolah di Indonesia Menurut Karakteristik Keluarga. Penelit Gizi dan Makanan -The J Nutr Food Res. 2013;36(2):121-6.

21. Edi N, Sukoco W, Pambudi J, Herawati MH. Hubungan Status Gizi Anak Balita Dengan Orang Tua Bekerja (Relationship Between Nutritional Status of Children Under Five with Parents Who Work). Buletin Penelitian Sistem Kesehatan. 2015;18(4).

22. Soekirman; Hardinsyah; Idrus Jus, at; Abas Basuni Jahari. Food and Nutrition Bulletin, vol. 23, no. 1 (C) 2002, The United Nations University. 31 Regional Study of Nutrition- al Status of Urban Primary School Children West Jakarta and Bogor, Indonesia. Food Nutr Bull . 2002;23(1).

23. Kratěnová J, Žejglicová K, Malý M, Filipová V. Prevalence and Risk Factors of Poor Posture in School Children in the Czech Republic. J Sch Health. 2007 Mar 1;77(3):131-7.

24. Ostojić Z, Kristo T, Ostojić L, Petrović P, Vasilj I, Santić Z, et al. Prevalence of Scoliosis in School-Children from Mostar, Bosnia and Herzegovina. Coll Antropol. 2006 Mar;30(1):59-64.

25. Sterkowicz-przybycień KL, Sterkowicz S, Żarów RT. Somatotype, Body Composition and Proportionality in Polish Top Greco-Roman Wrestlers. J Hum Kinet. 2011:28(28) 141-154.

26. Fu K-MG, Smith JS, Polly DW, Ames CP, Berven SH, Perra JH, et al. Morbidity and Mortality Associated with Spinal Surgery in Children: a Review of the Scoliosis Research Society Morbidity and Mortality Database. J Neurosurg Pediatr. 2011 Jan;7(1):37-41.

27. Morais T, Bernier M, Turcotte F. Age and Sex Specific Prevalence of Scoliosis and the Value of School Screening Programs. Am J Public Health. 1985 Dec;75(12):1377-80. 